\title{
Effect of different basin materials on the performance of hemispherical distiller with mirrors and energy storage material
}

\section{Mohammed El Hadi Attia}

Universite d'El Oued

\section{Fadl Abdelmonem Essa}

Kafrelsheikh University

\section{Mohamed Abdelgaied}

Tanta University Faculty of Engineering

Abd elnaby Kabeel ( $\square$ kabeel6@f-eng.tanta.edu.eg)

Tanta University Faculty of Engineering

\section{Research Article}

Keywords: Solar energy, Hemispherical solar still, Basin's materials, Reflectors mirrors, Sand grains, Energy storage

Posted Date: January 14th, 2022

DOI: https://doi.org/10.21203/rs.3.rs-1170410/v1

License: (9) (1) This work is licensed under a Creative Commons Attribution 4.0 International License. Read Full License 


\section{Abstract}

Numerous studies are being conducted on solar desalination systems with creating new designs to improve the efficiency and yield of these systems. Hemispherical solar still has a relatively large throughput because of its large exposure and evaporation surface areas compared to the other distiller designs. To get the optimal conditions of the parameters that provide the highest productivity of the hemispherical still, three hemispherical basin stills were fabricated and tested. The experiments were performed in three stages: In the first one, the traditional hemispherical solar still THSS (a reference distiller) was compared by THSS with internal reflective mirrors (THSS-IRM). In the second stage, the effect of using different basin metals (THSS with basin metal of zinc (THSS-IRMZ) and basin metal of copper (THSS-IRMC)) with internal reflective mirrors was studied. In the third stage, the two distillers were investigated under using energy storage medium ( $30 \mathrm{~g} / \mathrm{L}$ sand grains for each). The THSS with internal reflective mirrors, basin metal of zinc, and energy storage medium is abbreviated by THSS-IRMZSG. Also,

THSS with internal reflective mirrors, basin metal of copper, and energy storage medium is abbreviated by THSS-IRMCSG. Moreover, THSS with internal reflective mirrors and energy storage medium is abbreviated by THSS-IRMSG. The results showed that the combination of using internal reflective mirrors, basin material (copper) and energy storage medium provided the best improvement of hemispherical distillation device. The maximum cumulative yield of THSS-IRMCSG was $11.9 \mathrm{~L} / \mathrm{m}^{2}$. day, while the reference distillation device gave a total yield of $4.65 \mathrm{~L} / \mathrm{m}^{2}$.day. So, the productivity was improved by around $156 \%$.

\section{Introduction}

Although the food, energy, and water are the basic needs for the human beings, there is a big shortage of these stuffs all over the world (Tiwari \&Sahota 2017). Also, any sustainability plan for any country is mainly dependent on the food-energy-water nexus. Various ways like solar-based multi-generation units and greenhouse-solar distillation units are proposed to solve the problems the people suffer from (Essa et al. 2020c). Solar thermal desalination like MSF (Harandi et al. 2017), HDH (Abdullah et al. 2020a, Essa et al. 2020f, Sharshir et al. 2016), MEB (Darwish et al. 2006), and solar stills (Kabeel et al. 2014b, a) is one of the methods that help solving the water shortage problem (Elsheikh et al. 2018).

The solar distillers are devices easy to fabricate and do not need intelligent skills, but they suffer from the low productivity (Essa et al. 2020d, Essa et al. 2020c). This motivated the scientists to find different methods to improve the productivity of the distillers. As a consequence, different designs and modifications can be found in the literature of solar stills, and all these modifications aimed to enhance the solar still performance. The modifications are like stepped (Essa et al. 2020b), disc (Essa et al. 2020e), tubular (Elashmawy 2020, Kabeel et al. 2020), drum (Abdullah et al. 2019b), PV/T active distiller (Hedayati-Mehdiabadi et al. 2020, Pounraj et al. 2018), finned (Omara et al. 2011a), trays (Abdullah et al. 2020b, Abdullah et al. 2020c), inclined (Kumar et al. 2017), wick (Abdullah et al. 2019a, Abdullah et al. 2018, Omara et al. 2015a), corrugated (Omara et al. 2016, Omara et al. 2015b), distiller with condenser (Kabeel et al. 2017), spherical (Modi et al. 2020), double-effect (Abderachid \&Abdenacer 2013, 
Rajaseenivasan et al. 2013, Rajaseenivasan \&Kalidasa Murugavel 2013), multi-stage (El-Sebaii 2005), distiller with nanofluids (Shanmugan et al. 2020), distiller with heat exchanger (Yadav 1991), inverted still (Suneja \&Tiwari 1999), and pyramid distillers (Modi \&Nayi 2020, Nayi \&Modi 2018). Moreover, the distillers were examined when utilizing nanomaterials (Kabeel et al. 2017, Thamizharasu et al. 2020), floating aluminum sheet (Valsaraj 2002), desiccant (Modi \&Shukla 2018), glass cooling (Sharshir et al. 2017b), rocks (Abdallah et al. 2009), wicks (Omara et al. 2015a), PCM (Sharshir et al. 2017a), fins (Omara et al. 2011b), sun-tracker (Abdallah \&Badran 2008), multi-effect basins (Al-Hinai et al. 2002), reflectors (Omara et al. 2016), and vapor extraction (Elashmawy \&Alshammari 2020, Essa et al. 2020a, Scrivani \&Bardi 2008).

Attia et al. (Attia et al. 2021c) studied experimentally the effect of using metal trays (copper, zinc and iron) fixed on the bottom of a hemispherical solar distillation device to improve its productivity. They concluded that the productivity reached its highest value of $7.35 \mathrm{~L} / \mathrm{m}^{2}$.day when using the copper trays compared to $4.8 \mathrm{~L} / \mathrm{m}^{2}$.day for that of conventional distiller. While it was 6.3 and $5.5 \mathrm{~L} / \mathrm{m}^{2}$.day when using zinc and iron trays, respectively. Attia et al. (Attia et al. 2021a) tested experimentally the performance of hemispherical still with and without phosphate pellets placed homogeneously at two concentrations (10 and $20 \mathrm{~g} / \mathrm{L}$ ) at the bottom of the basin. It was observed that the increase in productivity reached $47.9 \%$ when using phosphate pellets with a concentration of $(20 \mathrm{~g} / \mathrm{L})$ and reached $33.7 \%$ when using phosphate pellets with a concentration of $(10 \mathrm{~g} / \mathrm{L})$. Moreover, Attia et al. (Attia et al. 2021b) studied experimentally the effect of different concentrations of sand grains $(5,10,20,30,40,50,60$ and $70 \mathrm{~g} / \mathrm{L})$ to improve the hemispherical solar still performance. The results obtained that the optimal concentration of sand particles was $30 \mathrm{~g} / \mathrm{L}$, where the yield reached $7.27 \mathrm{~L} / \mathrm{m}^{2}$. day compared to $4.78 \mathrm{~L} / \mathrm{m}^{2}$.day for the still without grains of sand.

In addition, Khechekhouche et al. (Khechekhouche et al. 2021) studied the effect of using zinc plate (black metallic) to enhance the efficiency of the solar distiller. It was found that the daily production was $3.894 \mathrm{~L} / \mathrm{m}^{2}$. day when using the zinc plate versus $2.52 \mathrm{~L} / \mathrm{m}^{2}$.day for the distiller without the zinc plate. Essa et al. (Essa et al. 2021a) examined the impact of using internal and external reflectors o the performance of the trays solar still. They obtained an improved productivity by $104 \%$. Besides, Omara et al. (Omara et al. 2016) performed an experimental study of the corrugated solar still (CrSS) under outdoors conditions of Kafrelsheikh (Egypt). They investigated experimentally the possibility of using the layer wick and reflectors to enhance the productivity of the CrSS. It was observed that the productivity was enhanced by $145.5 \%$ as compared by the conventional still. Moreover, they deduced that the daily efficiency was $59 \%$ and $33 \%$ for the CrSS and conventional still, respectively.

The major goal of the current original paper is to examine experimentally for the first time, according to the authors' information, the effects of the parameters: different basin materials (basin metal of zinc and basin metal of copper), internal reflecting mirrors, and energy storage medium ( $30 \mathrm{~g} / \mathrm{L}$ sand grains) on the hemispherical distiller performance. The tests were performed in El Oued, Algeria through August 2020. 


\section{Experimentations}

\section{Test-rig fabrication}

Figure 1 shows the 2D design of the hemispherical solar basin still. This system had a circular base whose diameter was equal to $38 \mathrm{~cm}$ and height was $4 \mathrm{~cm}$. The basin was made of wood, $2.5 \mathrm{~cm}$ thick, and greased on all sides with black silicone. The transparent cover had a diameter of $40 \mathrm{~cm}$ and thickness of $3 \mathrm{~mm}$. Additionally, the distillate was collected with the help of a plastic tube fixed at the lower end of the suspended trough as illustrated in Figure 1.

To investigate the impact of using two different basin metal liners of copper and zinc that work as good thermal energy storing materials, we used the plates with the properties obtained in Table 1.

Table 1

Characteristics of investigated metals (Copper and Zinc).

\begin{tabular}{|lll|}
\hline Item (Unit) & Copper & Zinc \\
\hline Density $\left(\mathrm{g} / \mathrm{cm}^{3}\right)$ & 8.96 & 7.14 \\
\hline Melting Point $(\mathrm{K})$ & 1356.6 & 693 \\
\hline Boiling Point $(\mathrm{K})$ & 2840 & 1180 \\
\hline Thermal conductivity $\mathrm{W} /(\mathrm{m} \cdot \mathrm{K})$ & 401 & 116 \\
\hline
\end{tabular}

Table 2 obtains the X-ray fluorescence (XRF) of El Oued sand. The results indicate that the silica (silicon oxide) has a high concentration of $97.63 \%$ among the other oxides of the sand. Also, the remaining other oxides are appeared at low concentrations. 
Table 2

Chemical analysis of El Oued sand by X-ray fluorescence (XRF).

\begin{tabular}{|llll|}
\hline \multicolumn{3}{|l|}{ Concentrations of oxides (\%) } & \multicolumn{2}{l|}{ Concentrations of trace elements (ppm) } \\
\hline $\mathrm{SiO}_{2}$ & 97.63 & $\mathrm{Cl}$ & 425 \\
$\mathrm{MgO}$ & 0.613 & $\mathrm{Zn}$ & 44.0 \\
$\mathrm{CaO}$ & 0.564 & $\mathrm{Ba}$ & 21.0 \\
\hline $\mathrm{Na}_{2} \mathrm{O}$ & 0.542 & $\mathrm{Sr}$ & 6.00 \\
\hline $\mathrm{Al}_{2} \mathrm{O}_{3}$ & 0.327 & $\mathrm{Nb}$ & 5.00 \\
\hline $\mathrm{CO}_{2}$ & 0.105 & $\mathrm{Bi}$ & 5.00 \\
\hline $\mathrm{K}_{2} \mathrm{O}$ & 0.0677 & $\mathrm{Ge}$ & 3.00 \\
\hline $\mathrm{Fe}_{2} \mathrm{O}_{3}$ & 0.042 & & \\
\hline $\mathrm{SO}_{3}$ & 0.037 & & \\
\hline $\mathrm{P}_{2} \mathrm{O}_{5}$ & 0.0138 & & \\
\hline $\mathrm{TiO}_{2}$ & 0.0053 & & \\
\hline $\mathrm{MnO}^{2}$ & 0.0021 & \\
\hline
\end{tabular}

Figure 2 shows a micro photo of El Oued sand. It is discerned by its golden yellow colour. This is because of its chemical composition and granular components. Figure 2 illustrates the sizes of the sand grains and their diameter which is between 1.5 and $2 \mathrm{~mm}$.

The experimental test-rig is shown in Fig. 3. The tests were managed for three days of 16 th, 17 th, and 18th August 2020 for 12 hours (from 07:00 to 19:00) in El Oued, Algeria ( $06^{\circ} 47^{\prime} \mathrm{E}$ and $33^{\circ} 30^{\prime} \mathrm{N}$ ). The hemispherical distiller inner walls are covered by mirrors. Besides, the black painted liners of copper and zinc are fixed on the basin bottom to evaluate their impact on the daily output of the solar distillers. These plates metal liners present a circular area of $0.1 \mathrm{~m}^{2}$. The experiments were conducted in three stages: In the first stage, the traditional hemispherical solar still THSS (a reference distiller) was compared and THSS with internal reflective mirrors (THSS-IRM). In the second stage, the two distillates were compared with basin metal of zinc (THSS-IRMZ) and basin metal of copper (THSS-IRMC) and the internal reflective mirrors with the THSS with the internal reflective mirrors only. In the third stage, the two distillates were compared with energy storage medium ( $30 \mathrm{~g} / \mathrm{L}$ sand grains), the internal reflective mirrors and basin metal of zinc (THSS-IRMZSG) and basin metal of copper (THSS-IRMCSG) and the THSS with the internal reflective mirrors and energy storage medium ( $30 \mathrm{~g} / \mathrm{L}$ sand grains) (THSS-IRMSG). Table 3 obtains the errors occurred in the measuring instruments readings. 
Table 3

Standard uncertainties of instruments.

\begin{tabular}{|lllll|}
\hline Instrument & Unit & Accuracy & Range & Standard uncertainty \\
\hline Solar power meter & $\left(\mathrm{W} / \mathrm{m}^{2}\right)$ & \pm 10 & $0-1999$ & 5.72 \\
\hline Thermocouple & $\left({ }^{\circ} \mathrm{C}\right)$ & \pm 0.1 & $-100-500$ & 0.07 \\
\hline Measuring jar & $(\mathrm{mL})$ & \pm 1 & $0-250$ & $0.6 \mathrm{ml}$ \\
\hline
\end{tabular}

\section{Results And Discussion}

\section{Effect of using internal reflective mirrors}

The sun radiation and air temperature are the parameters that affect the performance of the distiller. Consequently, Fig. 4 shows the solar radiation and temperatures of air and elements of the system. The highest sun irradiance was at 12:00, where it was $1010 \mathrm{~W} / \mathrm{m}^{2}$. Also, Fig. 4 reveals that using the reflective mirrors increased the water temperature of THSS-IRM more than that of the THSS by $0-6^{\circ} \mathrm{C}$. The water elevated temperature of THSS-IRM might be referred to the higher amount of focused solar radiations inside the THSS-IRM as compared to that of THSS. Also, the water temperature was maximum at noon time, where it was 68 and $72^{\circ} \mathrm{C}$ for THSS and THSS-IRM, respectively. This was due to that the solar radiation and ambient temperature were maximum at noon time. Additionally, Fig. 4 shows that the glass of THSS-IRM had a temperature more than that of THSS by $0-1^{\circ} \mathrm{C}$. Furthermore, it was maximal at noon time, where it was 53 and $54^{\circ} \mathrm{C}$ for THSS and THSS-IRM, respectively. The increase in glass temperature of THSS-IRM was referred to the increased generated vapor inside THSS-IRM compared to that of the THSS.

Moreover, the productivity of the THSS and THSS-IRM is shown in Fig. 5. It can be revealed that the productivity of the solar still follows the solar radiation either by increasing or decreasing. Fig. 5 illustrates that the instantaneous yield is maximal at noontime (14:00), where it was 700 and 900 $\mathrm{mL} / \mathrm{m}^{2}$.hr for THSS and THSS-IRM, respectively. Also, it is obtained that THSS-IRM introduced better productivity than the THSS. This is due to the use of the internal reflective mirrors inside the THSS-IRM, which improves the vaporization of THSS-IRM compared to THSS. Then, the greater the evaporation in the solar still is, the higher the yield is. Also, using internal reflective mirrors improved the evaporation of the THSS-IRM. So, the instantaneous yield of THSS-IRM was greater than that of THSS, Fig. 5. Furthermore, the total distillates of the THSS and THSS-IRM when using internal reflective mirrors are calculated to get the daily yield rise of THSS-IRM over that of THSS. The results obtained that the cumulative daily yield of THSS-IRM was more than that of THSS. The distillates of THSS-IRM and THSS were 7000 and $4650 \mathrm{~mL} / \mathrm{m}^{2}$.day, respectively. So, THSS-IRM augmented the yield by $50.5 \%$ over THSS because of the well explained reasons above.

\section{Effect of using different basin liner metals of zinc and copper}


Figure 6 obtains the irradiance and temperatures of solar stills at internal reflective mirrors and different basin metals (zinc and copper). The highest sun irradiance was at 12:00. Also, Figure 6 reveals that using the reflective mirrors and basin metals increased the water temperature of THSS-IRMZ and THSS-IRMC more than that of the THSS-IRM by around $0-3^{\circ} \mathrm{C}$ and $0-6^{\circ} \mathrm{C}$, respectively. The water elevated temperature of THSS-IRMZ and THSS-IRMC might be referred to the enhanced heat transfer properties due to using the basin metals of zinc and copper compared to the conventional basin material of iron. Also, the water temperature was maximum at noon time, where it was 72,76 , and $78^{\circ} \mathrm{C}$ for the THSS-IRM, THSS-IRMZ, and THSS-IRMC, respectively. This was due to that the solar radiation and ambient temperature were maximum at noon time. Additionally, Figure 6 shows that the glass temperatures of THSS-IRMZ and THSS-IRMC were almost the same, and they were more than that of THSS by $0-1^{\circ} \mathrm{C}$. What is more, the glass temperature is maximal at noontime, where it was 52,53 , and $53^{\circ} \mathrm{C}$ for the THSSIRM, THSS-IRMZ, and THSS-IRMC, respectively. The increase in glass temperature of THSS-IRMZ and THSS-IRMC was referred to the increased generated vapor compared to that of the THSS-IRM.

In addition, the hourly and total accumulated productivity of the solar stills (THSS-IRM, THSS-IRMZ, and THSS-IRMC) are drawn in Fig. 7. The freshwater yield has the same behavior of the solar radiation obtained in Fig. 6 . The yield increases gradually from the morning time to noon and begins to decrease after that with decreasing the solar radiation. The instantaneous yield is maximal at 14:00, where it reported 900, 1100, and $1150 \mathrm{~mL} / \mathrm{m}^{2}$.hr for THSS-IRM, THSS-IRMZ, and THSS-IRMC, respectively. Also, the THSS-IRMC introduced more productivity than either THSS-IRM or THSS-IRMZ. This was due to the improved heat transfer characteristics of the copper basin materials as compared to that of the iron and zinc. This led to enhance the vaporization of the THSS-IRMC more than the other solar stills. So, the THSS-IRMC hourly yield was greater than that of either THSS-IRM or THSS-IRMZ as illustrated from Fig. 7. In addition, using internal reflective mirrors with copper and zinc basin materials augmented the freshwater yield of the distillers as illustrated in Fig. 7. The results obtained that the total distilled water of THSS-IRMC was more than that of either THSS-IRM or THSS-IRMZ. As a result, the accumulated distillate of the THSS-IRMC, THSS-IRMZ, and THSS-IRM was 9500, 8550, and $7000 \mathrm{~mL} / \mathrm{m}^{2}$.day, respectively. So, the productivity of THSS-IRMC and THSS-IRMZ was improved by around $35.7 \%$ and $22.1 \%$ over the THSS-IRM because of the above explicated causes of productivity enhancement. Moreover, the yield of THSS-IRMC and THSS-IRMZ was improved by around $104.3 \%$ and $84 \%$ over the THSS.

\section{Effect of using sand grains}

To avoid the repetition of results, we preferred to summarize the data of this section. The experimental results obtained that using the reflective mirrors with basin metals of zinc and copper and energy storage medium increased the water temperature of THSS-IRMZSG and THSS-IRMCSG more than that of the THSS-IRMSG by around $0-5^{\circ} \mathrm{C}$ and $0-8^{\circ} \mathrm{C}$, respectively throughout the day. Also, using the energy storage medium only increased the water temperature inside the solar distiller by around $0-3^{\circ} \mathrm{C}$. Besides, the water temperature was maximum at noon time, where it was 78,81 , and $84^{\circ} \mathrm{C}$ for the THSSIRMSH, THSS-IRMZSG, and THSS-IRMCSG, respectively. Additionally, the glass temperatures of THSSIRMZSG and THSS-IRMCSG were almost the same, and they were more than that of THSS by $0-1^{\circ} \mathrm{C}$. 
What is more, the glass temperature is maximal at noontime, where it was 54,55 , and $55^{\circ} \mathrm{C}$ for the THSSIRMSG, THSS-IRMZSG, and THSS-IRMCSG, respectively.

Furthermore, the hourly and total accumulated yield of the distillers (THSS-IRMSG, THSS-IRMZSG, and THSS-IRMCSG) are drawn in Fig. 8. The hourly yield was maximal at 14:00, where it was 1150, 1300, and $1400 \mathrm{~mL} / \mathrm{m}^{2}$.hr for THSS-IRMSG, THSS-IRMZSG, and THSS-IRMCSG, respectively. Also, the THSSIRMCSG introduced more productivity than either THSS-IRMSG or THSS-IRMZSG. This was due to the improved heat transfer characteristics of the copper basin materials as compared to that of the iron and zinc. Also, it was because the stored energy, by the energy storage medium, that released at the ties of sun absence. This led to enhance the vaporization of the THSS-IRMCSG more than the other solar stills. So, the hourly yield of THSS-IRMCSG was superior to that of either THSS-IRMSG or THSS-IRMZSG as illustrated from Fig. 8. Besides, the results obtained that the total freshwater production of THSS-IRMCSG was better than that of either THSS-IRMSG or THSS-IRMZSG. As a result, the accumulated distillate of the THSS-IRMCSG, THSS-IRMZSG, and THSS-IRMSG was 11900, 10800, and $9400 \mathrm{~mL} / \mathrm{m}^{2}$.day, respectively. So, the productivity of THSS-IRMC and THSS-IRMZ was improved by around $26.6 \%$ and $15 \%$ over the THSS-IRMSG. Moreover, the yield of THSS-IRMCSG and THSS-IRMZSG was improved by around $156 \%$ and $132.3 \%$ over the THSS.

\section{Comparison of present work with published similar works}

A comparison between the findings of the current work and the published similar works is obtained in Table 4. It is revealed that the total yield of THSS-IRM (solar still with internal mirrors) was increased by $50.5 \%$ compared to the traditional hemispherical solar distiller (THSS). Also, the cumulative yield was increased by $84 \%$ when using metal basin of zinc and internal reflective mirrors (THSS-IRMZ), by $104.3 \%$, when using metal basin of copper and internal reflective mirrors (THSS-IRMC), by $132.3 \%$ when using internal reflective mirrors, metal basin of zinc and sand grains (THSS-IRMZSG), and by $156 \%$ when using internal reflective mirrors, metal basin of copper and sand grains (THSS-IRMCSG). Thus, the internal reflective mirrors, metals sheets and sand grains greatly augmented the yield of the solar still.

Data of Table 4 obtained that the corrugated distiller productivity (Kumar et al. 2008) was minimal (11.92\%). Nevertheless, the trays distiller had maximal value (75\%) (Abdullah et al. 2020c). 
Table 4

Comparison between the findings of previous published works and current study.

\begin{tabular}{|c|c|c|c|}
\hline Author name & Type of SS & Enhancement techniques & $\begin{array}{l}\text { Productivity } \\
\text { (\%) }\end{array}$ \\
\hline \multirow[t]{6}{*}{ Our results } & \multirow{6}{*}{$\begin{array}{l}\text { Hemispherical } \\
\text { still }\end{array}$} & - Internal reflective mirrors & 50.5 \\
\hline & & $\begin{array}{l}\text { - Zinc basin metal and internal } \\
\text { reflective mirrors }\end{array}$ & \\
\hline & & - Copper basin metal and internal & 104.3 \\
\hline & & mirrors & 132.3 \\
\hline & & $\begin{array}{l}\text { - Internal mirrors, Zinc basin metal } \\
\text { and sand grains }\end{array}$ & 156 \\
\hline & & $\begin{array}{l}\text { - Internal mirrors, Copper basin metal } \\
\text { and sand grains }\end{array}$ & \\
\hline \multirow{3}{*}{$\begin{array}{l}\text { Attia et al. (Attia et al. } \\
\text { 2021c) }\end{array}$} & \multirow{3}{*}{$\begin{array}{l}\text { Trays } \\
\text { Hemispherical } \\
\text { SS }\end{array}$} & - Tray of Iron & 14.6 \\
\hline & & - Tray of Zinc & 31.25 \\
\hline & & - Tray of Copper & 53.125 \\
\hline Attia et al. (Attia et al.) & Single slope SS & Bed Phosphate & 16.8 \\
\hline \multirow{2}{*}{$\begin{array}{l}\text { Kumar et al. (Kumar et al. } \\
\text { 2008) }\end{array}$} & \multirow[t]{2}{*}{ "V" type SS } & - Mirror & 11.92 \\
\hline & & - Mirror and charcoal & 14.11 \\
\hline \multirow{2}{*}{$\begin{array}{l}\text { Abdullah et al. (Abdullah } \\
\text { et al. 2020c) }\end{array}$} & \multirow[t]{2}{*}{ Trays SS } & - Internal reflectors & 58.00 \\
\hline & & - External reflectors & 75.00 \\
\hline \multirow{2}{*}{$\begin{array}{l}\text { Chandrika et al. } \\
\text { (Chandrika et al. 2021) }\end{array}$} & \multirow{2}{*}{$\begin{array}{l}\text { Single slope } \\
\text { still }\end{array}$} & - Reflective glass mirror & 68.57 \\
\hline & & - Reflective aluminum sheet & 48.57 \\
\hline
\end{tabular}

\section{Economic Analysis}

\section{Daily yield}

Table 5 presents the daily yield of the THSS, THSS-IRM, THSS-IRMZ, THSS-IRMC, THSS-IRMSG, THSSIRMZSG and THSS-IRMCSG. The experiments were recorded during 12 hours on August 16, 17 and 18, 2020. Then, the maximum daily yield was obtained with the THSS-IRMCSG (internal reflective mirrors and basin metal of copper and sand grains). 
Table 5

Cumulative yield of the solar stills under different conditions.

\begin{tabular}{|c|c|c|c|c|c|c|c|}
\hline Date & $\begin{array}{l}\text { THSS } \\
\left(\mathrm{kg} / \mathrm{m}^{2}\right)\end{array}$ & $\begin{array}{l}\text { THSS- } \\
\text { IRM } \\
\left(\mathrm{kg} / \mathrm{m}^{2}\right)\end{array}$ & $\begin{array}{l}\text { THSS- } \\
\text { IRMZ } \\
\left(\mathrm{kg} / \mathrm{m}^{2}\right)\end{array}$ & $\begin{array}{l}\text { THSS- } \\
\text { IRMC } \\
\left(\mathrm{kg} / \mathrm{m}^{2}\right)\end{array}$ & $\begin{array}{l}\text { THSS- } \\
\text { IRMSG } \\
\left(\mathrm{kg} / \mathrm{m}^{2}\right)\end{array}$ & $\begin{array}{l}\text { THSS- } \\
\text { IRMZSG } \\
\left(\mathrm{kg} / \mathrm{m}^{2}\right)\end{array}$ & $\begin{array}{l}\text { THSS- } \\
\text { IRMCSG } \\
\left(\mathrm{kg} / \mathrm{m}^{2}\right)\end{array}$ \\
\hline $16 / 08 / 2020$ & 4.65 & 7.00 & - & - & - & - & - \\
\hline $17 / 08 / 2020$ & & 7.00 & 8.55 & 9.50 & - & - & - \\
\hline $18 / 08 / 2020$ & & & & & 9.40 & 10.80 & 11.90 \\
\hline
\end{tabular}

\section{Economic Evaluation}

Table 6 obtains the costs of THSS and THSS-IRM. From these data, the daily water produced from THSS is $4.65 \mathrm{~kg} / \mathrm{m}^{2} /$ day with a daily water production price of 279 DZD, while the daily water produced from THSS-IRM is $7.00 \mathrm{~kg} / \mathrm{m}^{2} /$ day with a price of 420 DZD.

Table 6

Fabrication cost of the THSS and THSS-IMR. (1\$=132.78 DZD, $1 €=156.03$ DZD)

\begin{tabular}{|lll|}
\hline Parameter & HSS-WBS & HSS-RAS \\
\hline $\begin{array}{l}\text { Total cost of manufacturing } \\
\text { (DZD) }\end{array}$ & 9000 & 9000 \\
\hline Cost of internal mirrors & & 400 \\
\hline $\begin{array}{l}\text { Maintenance cost } \\
\text { (DZD) }\end{array}$ & 50 & 50 \\
\hline $\begin{array}{l}\text { Total fixed cost } \\
\text { (DZD) }\end{array}$ & 9050 & 9450 \\
\hline $\begin{array}{l}\text { Distillate productivity during the day (kg/m²/day) } \\
\text { Cost per liter of distilled water on the market (DZD) }\end{array}$ & 60 & 7.65 \\
\hline $\begin{array}{l}\text { The price of daily water production (DZD) } \\
\text { Recovery period }\end{array}$ & 279 & 420 \\
\hline
\end{tabular}

In addition, Table 7 presents the cost of THSS-IRM, THSS-IRMZ and THSS-IRMC. From these results, it is clear that the daily water produced from THSS-IRM is $7.00 \mathrm{~kg} / \mathrm{m}^{2} /$ day with a price of $420 \mathrm{DZD}$, while the daily water obtained from THSS-IRMZ is $8.55 \mathrm{~kg} / \mathrm{m}^{2} /$ day with a price equal to 513 DZD. Also, the daily water obtained from THSS-IRMC is $9.50 \mathrm{~kg} / \mathrm{m}^{2} /$ day with a price of 570 DZD. 
Table 7

Fabrication cost of the THSS-IRM, THSS-IRMZ and THSS-IRMC. (1 $\$=132.78$ DZD, $1 €=156.03$ DZD)

\begin{tabular}{|llll|}
\hline Parameter & $\begin{array}{l}\text { THSS- } \\
\text { IRM }\end{array}$ & $\begin{array}{l}\text { THSS- } \\
\text { IRMZ }\end{array}$ & $\begin{array}{c}\text { THSS- } \\
\text { IRMC }\end{array}$ \\
\hline $\begin{array}{l}\text { Total cost of manufacture } \\
\text { (DZD) }\end{array}$ & 9000 & 9000 & 9000 \\
\hline The price of basin metal & - & 600 & 900 \\
\hline The price of internal reflective mirrors & 400 & 400 & 400 \\
\hline Maintenance cost (DZD) & 50 & 50 & 50 \\
\hline Total cost (DZD) & 9450 & 10050 & 10350 \\
\hline $\begin{array}{l}\text { The amount of water produced during the day } \\
\text { (kg/m }{ }^{2} / \text { day) }\end{array}$ & 7.00 & 8.55 & 9.50 \\
\hline $\begin{array}{l}\text { Market water cost for one liter (DZD) } \\
\text { The price of daily water production (DZD) }\end{array}$ & 60 & 60 & 60 \\
\hline Recovery period & 420 & 513 & 570 \\
\hline
\end{tabular}

Besides, Table 8 shows the fabrication costs of the THSS-IRMSG, THSS-IRMZSG and THSS-IRMCSG. From these results, the daily water produced from THSS-IRMSG is $9.40 \mathrm{~kg} / \mathrm{m}^{2} /$ day with a price of 564 DZD, while the value of the daily water obtained from THSS-IRMZSG is $10.80 \mathrm{~kg} / \mathrm{m}^{2} /$ day with a price equal to 648 DZD. Moreover, the daily water produced from THSS-IRMCSG is $11.90 \mathrm{~kg} / \mathrm{m}^{2} /$ day with a price of 155.91 DZD. 
Table 8

Fabrication cost of the THSS-IRMSG, THSS-IRMZSG and THSS-IRMCSG. $(1 \$=132.78$ DZD, $1 €=156.03$ DZD)

\begin{tabular}{|llll|}
\hline Parameter & $\begin{array}{c}\text { THSS- } \\
\text { IRMSG }\end{array}$ & $\begin{array}{l}\text { THSS- } \\
\text { IRMZSG }\end{array}$ & $\begin{array}{c}\text { THSS- } \\
\text { IRMCSG }\end{array}$ \\
\hline $\begin{array}{l}\text { Total cost of manufacture } \\
\text { (DZD) }\end{array}$ & 9000 & 9000 & 9000 \\
\hline The price of basin metal & - & 600 & 900 \\
\hline The price of sand free & 00 & 00 & 00 \\
\hline The price of internal reflective mirrors & 400 & 400 & 400 \\
\hline Maintenance cost (DZD) & 50 & 50 & 50 \\
\hline Total cost (DZD) & 9450 & 10050 & 10350 \\
\hline $\begin{array}{l}\text { The amount of water produced during the day } \\
\text { (kg/m }{ }^{2} / \text { day) }\end{array}$ & 9.40 & 10.80 & 11.90 \\
\hline $\begin{array}{l}\text { The cost per liter of distilled water on the market } \\
\text { (DZD) }\end{array}$ & 60 & 60 & 60 \\
\hline \begin{tabular}{l} 
The price of daily water production (DZD) \\
\hline Recovery period
\end{tabular} & 564 & 648 & 714 \\
\hline
\end{tabular}

\section{Efficiency of solar stills}

The thermal efficiency of the distiller is evaluated by (Abdullah et al. 2019b, Kabeel et al. 2017);

$\eta_{\mathrm{d}}=\frac{\sum \dot{\mathrm{m}} \times \mathrm{h}_{\mathrm{fg}}}{\sum \mathrm{A} \times \mathrm{I}}$

Where $\eta_{d}$ is the daily efficiency, $\dot{m}$ is the hourly yield, $h_{f g}$ is the latent heat, $A$ is the projected area, and I is the daily average irradiance. Moreover, $\mathrm{h}_{\mathrm{fg}}$ is calculated based on the water temperature $\left(\mathrm{T}_{\mathrm{w}}\right)$ as following (Essa et al. 2021b, Tiwari \&Sahota 2017);

$h_{f g}=3.1625 \times 10^{6}+\left[1-\left(7.616 \times 10^{-4} \times T_{w}\right]\right.$ for $T_{w}>70^{\circ} \mathrm{C}(2)$

$h_{f g}=2.4935 \times 10^{6}\left[1-\left(9.4779 \times 10^{-4} \times T_{w}\right)+\left(1.3132 \times 10^{-7} \times T_{w}^{2}\right)-\left(4.7974 \times 10^{-9} \times T_{w}^{3}\right)\right]$ for $T_{w}<70^{\circ} \mathrm{C}$

Based on the above equations, the highest thermal efficiency was obtained for the THSS-IRMCSG, where it was $48 \%$ compared to $28 \%$ for the traditional hemispherical solar still (THSS).

\section{Conclusions}


This experimental work investigates the effects of using internal reflective mirrors, basin metals and sand grains on the productivity and efficiency of the hemispherical solar still. This simple technique involves placing an internal reflective mirror on the inner walls of the hemispherical solar still with different basin liner metals (zinc and copper) and sand grains. The obtained conclusions can be written as follows:

The internal reflective mirrors increased the heating of the saline water inside the basin by reflecting extra solar radiation on it.

Using the internal reflective mirrors and high thermal conductivity basin metals (zinc and copper) and phosphate granules enhanced significantly the performance of the solar still.

The distilled water production from the THSS and THSS-IRM was 4.65 and $7.00 \mathrm{~kg} / \mathrm{m}^{2} /$ day, respectively.

The distilled water production from the THSS-IRMZ and THSS-IRMC was 8.55 and $9.50 \mathrm{~kg} / \mathrm{m}^{2} / \mathrm{day}$, respectively.

The distillate production from the THSS-IRMSG, THSS-IRMZSG, and THSS-IRMCSG was 9.40, 10.80, and $11.90 \mathrm{~kg} / \mathrm{m}^{2} /$ day, respectively.

Using the internal reflective mirrors improved the productivity by $50.6 \%$ as compared to that of the THSS.

Using the basin metal of zinc and copper with internal reflective mirrors enhanced the distillate by 84 and $104.30 \%$ compared to that of the THSS, respectively.

The daily distillate of THSS-IRMSG, THSS-IRMZSG and THSS-IMRCSG was augmented by $102.15,132.3$ and $156 \%$ as compared to that of the THSS, respectively.

The best thermal performance of the solar still was obtained when using the basin metal of copper, sand grains, and internal reflective mirrors.

Based on the above conclusions, it can be reported that the reflective mirrors, high thermal conductivity basin metals, and sand grains improved greatly the productivity and efficiency of the solar distillation unit. Therefore, these modifications are recommended to be used in such applications.

\section{Abbreviations}


THSS

Traditional Hemispherical Solar Still

THSS-IRM Traditional Hemispherical Distiller with Internal Mirrors

THSS- $\quad$ Traditional Hemispherical Distiller with Internal Mirrors and basin metal of Zinc IRMZ

THSS- $\quad$ Traditional Hemispherical Distiller with Internal Mirrors and basin metal of Copper IRMC

THSS- $\quad$ Traditional Hemispherical Solar Still with an Internal Reflective Mirrors and sand grains IRMSG

THSS- $\quad$ Traditional Hemispherical Solar Still with an Internal Reflective Mirrors, basin metal of IRMZSG Zinc sand grains

THSS- $\quad$ Traditional Hemispherical Solar Still with an Internal Reflective Mirrors, basin metal of IRMCSG Copper and sand grains

\section{Declarations}

\section{Ethical Approval}

Not applicable

\section{Consent to Participate}

Not applicable

\section{Consent to Publish}

Not applicable

Authors Contributions

Author's full name Authors Contributions

1 Mohammed El Hadi Attia, Expermental work, , Writing - original draft, preparation.

2 Fadl Abdelmonem Essa, Formal analysis and investigation. Writing -Review \& Editing.

3-Mohamed Abdelgaied, Conceptualization, Me 441 thodology, Writing -,Review \&

Editing.

4 Abd Elnaby Kabeel, Conceptualization, Writing - Review \&Editing.Supervisor 
Funding

No any funding used in this paper

Competing Interests

No competing interests

Availability of data and materials

Not applicable

\section{References}

1. Abdallah S, Badran O (2008) Sun tracking system for productivity enhancement of solar still. Desalination 220:669-676

2. Abdallah S, Abu-Khader MM, Badran O (2009) Effect of various absorbing materials on the thermal performance of solar stills. Desalination 242:128-137

3. Abderachid T, Abdenacer K (2013) Effect of orientation on the performance of a symmetric solar still with a double effect solar still (comparison study). Desalination 329:68-77

4. Abdullah A, Essa F, Omara Z, Bek M (2018) Performance evaluation of a humidificationdehumidification unit integrated with wick solar stills under different operating conditions. Desalination 441:52-61

5. Abdullah A, Alarjani A, Al-sood MA, Omara Z, Kabeel A, Essa F (2019a) Rotating-wick solar still with mended evaporation technics: Experimental approach. Alexandria Engineering Journal 58:14491459

6. Abdullah A, Essa F, Omara Z, Rashid Y, Hadj-Taieb L, Abdelaziz G, Kabeel A (2019b) Rotating-drum solar still with enhanced evaporation and condensation techniques: Comprehensive study. Energy Convers Manage 199:112024

7. Abdullah A, Omara Z, Bek M, Essa F (2020a) An augmented productivity of solar distillers integrated to HDH unit: Experimental implementation. Appl Therm Eng 167:114723

8. Abdullah AS, Essa FA, Bacha HB, Omara ZM (2020b) Improving the trays solar still performance using reflectors and phase change material with nanoparticles. Journal of Energy Storage 31:101744

9. Abdullah AS, Younes MM, Omara ZM, Essa FA (2020c) New design of trays solar still with enhanced evaporation methods - Comprehensive study. Sol Energy 203:164-174

10. Al-Hinai H, Al-Nassri M, Jubran B (2002) Effect of climatic, design and operational parameters on the yield of a simple solar still. Energy Convers Manage 43:1639-1650

11. Attia MEH, Driss Z, Kabeel AE, Afzal A, Manokar AM Sathyamurthy R Phosphate bed as energy storage materials for augmentation of conventional solar still productivity. Environmental Progress \& Sustainable Energy, e13581 
12. Attia MEH, Abdelgaied M, El-Maghlany WM, Driss Z (2021a) : Enhancement of the performance of hemispherical distiller via phosphate pellets as energy storage medium.Environ. Sci. Pollut. Res.,110

13. Attia MEH, Kabeel A, Abdelgaied M (2021b) Optimal concentration of El Oued sand grains as energy storage materials for enhancement of hemispherical distillers performance. Journal of Energy Storage 36:102415

14. Attia MEH, Kabeel AE, Abdelgaied M, Essa FA, Omara ZM (2021c) Enhancement of hemispherical solar still productivity using iron, zinc and copper trays. Sol Energy 216:295-302

15. Chandrika VS, Attia MEH, Manokar AM, Marquez FPG, Driss Z, Sathyamurthy R (2021) : Performance enhancements of conventional solar still using reflective aluminium foil sheet and reflective glass mirrors: energy and exergy analysis.Environ. Sci. Pollut. Res.,1-9

16. Darwish MA, Al-Juwayhel F, Abdulraheim HK (2006) Multi-effect boiling systems from an energy viewpoint. Desalination 194:22-39

17. El-Sebaii A (2005) Thermal performance of a triple-basin solar still. Desalination 174:23-37

18. Elashmawy M (2020) Improving the performance of a parabolic concentrator solar tracking-tubular solar still (PCST-TSS) using gravel as a sensible heat storage material. Desalination 473:114182

19. Elashmawy M, Alshammari F (2020) Atmospheric water harvesting from low humid regions using tubular solar still powered by a parabolic concentrator system. J Cleaner Prod 256:120329

20. Elsheikh A, Sharshir S, Mostafa ME, Essa F, Ali MKA (2018) Applications of nanofluids in solar energy: a review of recent advances. Renewable Sustainable Energy Rev 82:3483-3502

21. Essa F, Elsheikh AH, Sathyamurthy R, Manokar AM, Kandeal A, Shanmugan S, Kabeel A, Sharshir SW, Panchal H, Younes M (2020a) Extracting water content from the ambient air in a double-slope halfcylindrical basin solar still using silica gel under Egyptian conditions. Sustain Energy Technol Assess 39:100712

22. Essa F, Omara Z, Abdullah A, Shanmugan S, Panchal H, Kabeel A, Sathyamurthy R, Alawee WH, Manokar AM, Elsheikh AH (2020b) Wall-suspended trays inside stepped distiller with $\mathrm{Al}_{2} \mathrm{O}_{3} /$ paraffin wax mixture and vapor suction: Experimental implementation. Journal of Energy Storage 32:102008

23. Essa F, Abdullah A, Omara Z, Kabeel A, Gamiel Y (2021a) Experimental study on the performance of trays solar still with cracks and reflectors. Appl Therm Eng 188:116652

24. Essa F, Alawee WH, Mohammed SA, Abdullah A, Omara Z (2021b) Enhancement of pyramid solar distiller performance using reflectors, cooling cycle, and dangled cords of wicks. Desalination 506:115019

25. Essa FA, Abd Elaziz M, Elsheikh AH (2020c) Prediction of power consumption and water productivity of seawater greenhouse system using random vector functional link network integrated with artificial ecosystem-based optimization. Process Saf Environ Prot 144:322-329

26. Essa FA, Abd Elaziz M, Elsheikh AH (2020d) An enhanced productivity prediction model of active solar still using artificial neural network and Harris Hawks optimizer. Appl Therm Eng 170:115020 
27. Essa FA, Abdullah AS, Omara ZM (2020e) Rotating discs solar still: New mechanism of desalination. J Cleaner Prod 275:123200

28. Essa FA, Abdullah AS, Omara ZM, Kabeel AE, El-Maghlany WM (2020f) : On the different packing materials of humidification-dehumidification thermal desalination techniques - A review.J. Cleaner Prod.,123468

29. Harandi HB, Rahnama M, Jahanshahi Javaran E, Asadi A (2017) Performance optimization of a multi stage flash desalination unit with thermal vapor compression using genetic algorithm. Appl Therm Eng 123:1106-1119

30. Hedayati-Mehdiabadi E, Sarhaddi F, Sobhnamayan F (2020) Exergy performance evaluation of a basin-type double-slope solar still equipped with phase-change material and PV/T collector. Renewable Energy 145:2409-2425

31. Kabeel A, Sathyamurthy R, Manokar AM, Sharshir SW, Essa F, Elshiekh AH (2020) Experimental study on tubular solar still using Graphene Oxide Nano particles in Phase Change Material (NPCM's) for fresh water production. Journal of Energy Storage 28:101204

32. Kabeel AE, Omara Z, Essa $F(2014 a)$ Improving the performance of solar still by using nanofluids and providing vacuum. Energy Convers Manage 86:268-274

33. Kabeel AE, Omara Z, Essa F (2014b) Enhancement of modified solar still integrated with external condenser using nanofluids: An experimental approach. Energy Convers Manage 78:493-498

34. Kabeel AE, Omara Z, Essa F (2017) Numerical investigation of modified solar still using nanofluids and external condenser. J Taiwan Inst Chem Eng 75:77-86

35. Khechekhouche A, Haoua BB, Attia MEH, El-Maghlany WM (2021) : Improvement of solar distiller productivity by a black metallic plate of Zinc as a thermal storage material.Journal of Testing and Evaluation49

36. Kumar BS, Kumar S, Jayaprakash R (2008) Performance analysis of a "V" type solar still using a charcoal absorber and a boosting mirror. Desalination 229:217-230

37. Kumar PN, Manokar AM, Madhu B, Kabeel AE, Arunkumar T, Panchal H, Sathyamurthy R (2017) Experimental investigation on the effect of water mass in triangular pyramid solar still integrated to inclined solar still. Groundwater for Sustainable Development 5:229-234

38. Modi KV, Shukla DL (2018) Regeneration of liquid desiccant for solar air-conditioning and desalination using hybrid solar still. Energy Convers Manage 171:1598-1616

39. Modi KV, Nayi KH (2020) Efficacy of forced condensation and forced evaporation with thermal energy storage material on square pyramid solar still. Renewable Energy 153:1307-1319

40. Modi KV, Nayi KH, Sharma SS (2020) Influence of water mass on the performance of spherical basin solar still integrated with parabolic reflector. Groundwater for Sustainable Development 10:100299

41. Nayi KH, Modi KV (2018) Pyramid solar still: A comprehensive review. Renew Sustain Energy Rev $81: 136-148$ 
42. Omara Z, Hamed MH, Kabeel A (2011a) Performance of finned and corrugated absorbers solar stills under Egyptian conditions. Desalination 277:281-287

43. Omara Z, Kabeel A, Essa F (2015a) Effect of using nanofluids and providing vacuum on the yield of corrugated wick solar still. Energy Convers Manage 103:965-972

44. Omara ZM, Hamed MH, Kabeel A (2011b) Performance of finned and corrugated absorbers solar stills under Egyptian conditions. Desalination 277:281-287

45. Omara ZM, Kabeel AE, Essa FA (2015b) Effect of using nanofluids and providing vacuum on the yield of corrugated wick solar still. Energy Convers Manage 103:965-972

46. Omara ZM, Kabeel AE, Abdullah AS, Essa FA (2016) Experimental investigation of corrugated absorber solar still with wick and reflectors. Desalination 381:111-116

47. Pounraj P, Winston DP, Kabeel A, Kumar BP, Manokar AM, Sathyamurthy R, Christabel SC (2018) Experimental investigation on Peltier based hybrid PV/T active solar still for enhancing the overall performance. Energy Convers Manage 168:371-381

48. Rajaseenivasan T, Elango T, Kalidasa Murugavel K (2013) Comparative study of double basin and single basin solar stills. Desalination 309:27-31

49. Rajaseenivasan T, Kalidasa Murugavel K (2013) Theoretical and experimental investigation on double basin double slope solar still. Desalination 319:25-32

50. Scrivani A, Bardi U (2008) A study of the use of solar concentrating plants for the atmospheric water vapour extraction from ambient air in the Middle East and Northern Africa region. Desalination 220:592-599

51. Shanmugan S, Essa FA, Gorjian S, Kabeel AE, Sathyamurthy R, Muthu Manokar A (2020) Experimental study on single slope single basin solar still using TiO2 nano layer for natural clean water invention. Journal of Energy Storage 30:101522

52. Sharshir S, Peng G, Wu L, Essa F, Kabeel A, Yang N (2017a) The effects of flake graphite nanoparticles, phase change material, and film cooling on the solar still performance. Appl Energy 191:358-366

53. Sharshir S, Peng G, Wu L, Yang N, Essa F, Elsheikh A, Mohamed SI, Kabeel A (2017b) Enhancing the solar still performance using nanofluids and glass cover cooling: experimental study. Appl Therm Eng 113:684-693

54. Sharshir SW, El-Samadony MOA, Peng G, Yang N, Essa FA, Hamed MH, Kabeel AE (2016) Performance enhancement of wick solar still using rejected water from humidificationdehumidification unit and film cooling. Appl Therm Eng 108:1268-1278

55. Suneja S, Tiwari GN (1999) Effect of water depth on the performance of an inverted absorber double basin solar still. Energy Conv Manag 40:1885-1897

56. Thamizharasu P, Shanmugan S, Gorjian S, Pruncu Cl, Essa FA, Panchal H, Harish M (2020) : Improvement of Thermal Performance of a Solar Box Type Cooker Using $\mathrm{SiO}_{2} / \mathrm{TiO}_{2} \mathrm{Nanolayer}$ Silicon 
57. Tiwari GN, Sahota L (2017) Advanced Solar-Distillation Systems: Basic Principles, Thermal Modeling, and Its Application. Springer

58. Valsaraj P (2002) An experimental study on solar distillation in a single slope basin still by surface heating the water mass. Renewable Energy 25:607-612

59. Yadav YP (1991) Performance analysis of a solar still coupled to a heat exchanger. Desalination $82: 243$

\section{Figures}

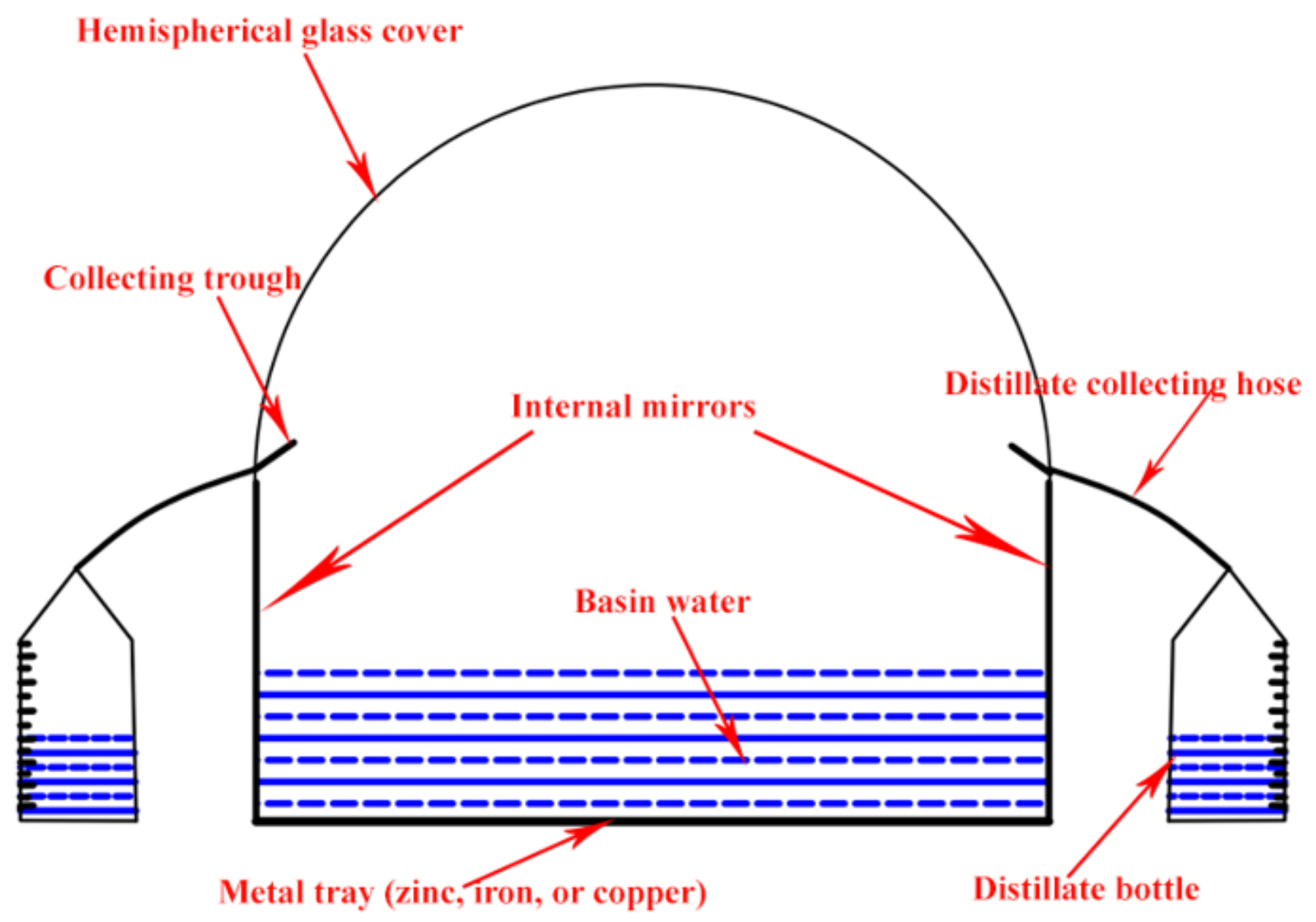

Figure 1

2D model of the hemispherical solar distiller. 


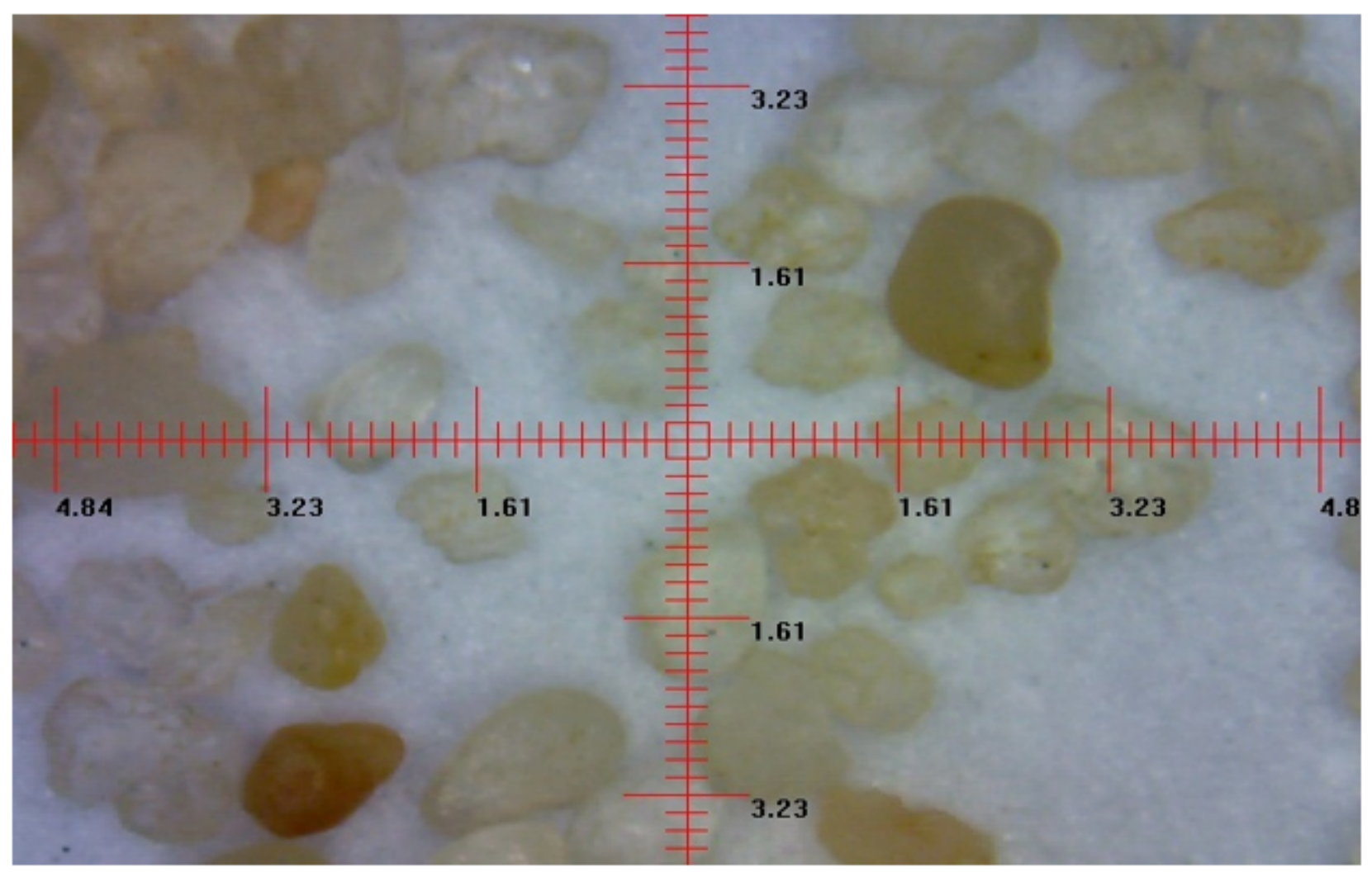

Figure 2

Micrograph of El-Oued sand grains. 

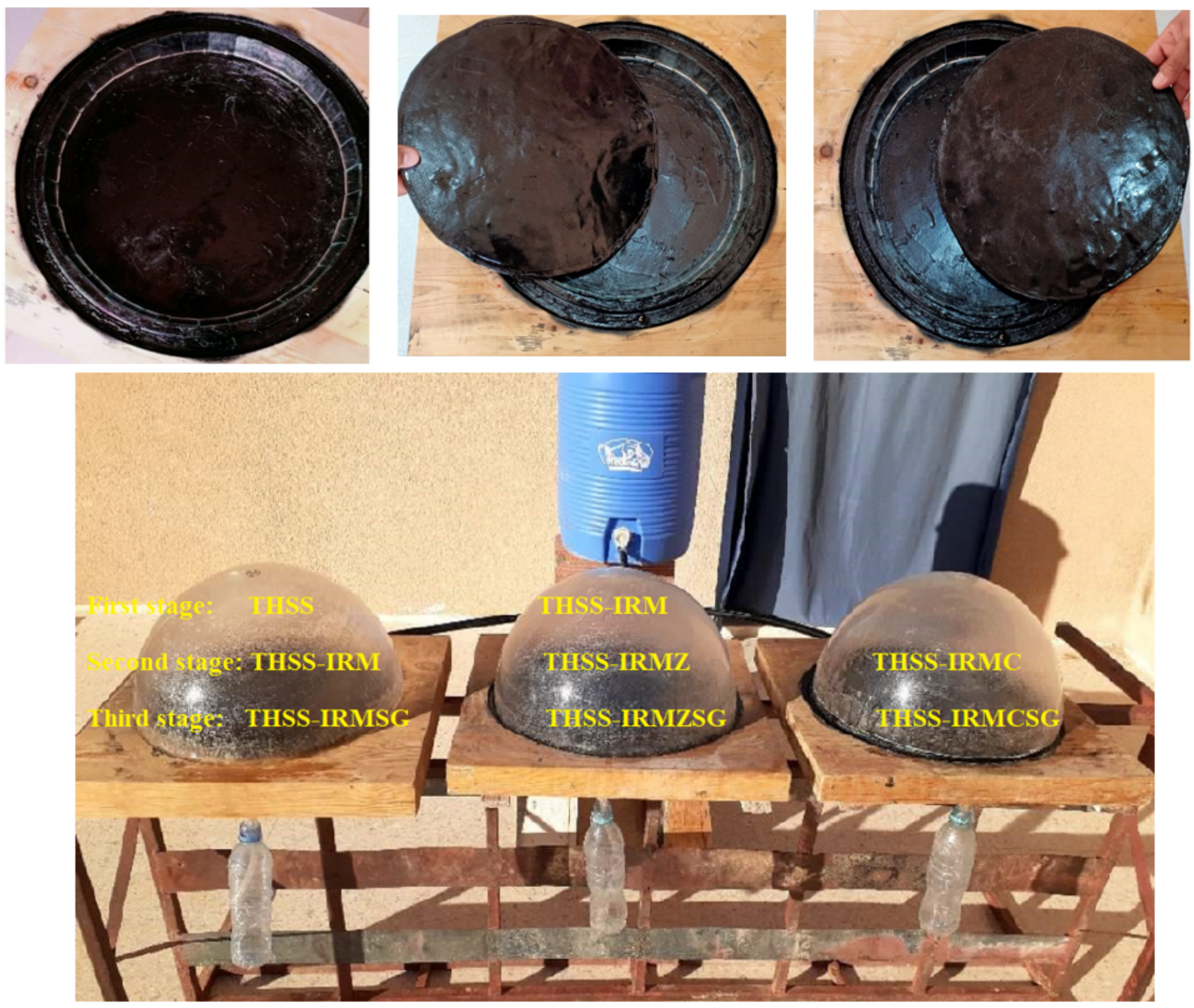

Figure 3

Investigated solar distillers. 


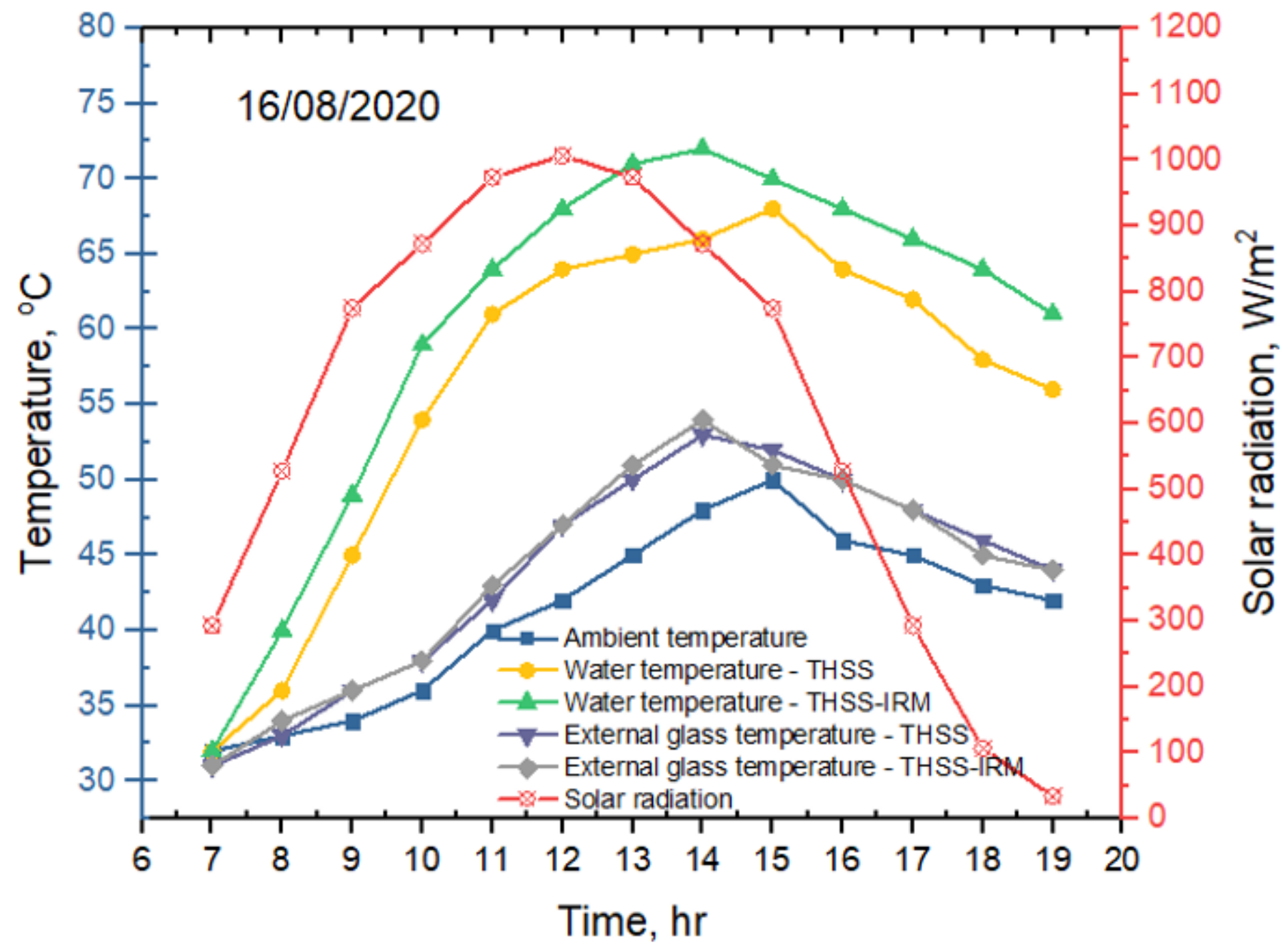

Figure 4

Environmental conditions for the test of using internal reflective mirrors. 




Figure 5

Hourly productivity of the THSS and THSS-IRM. 


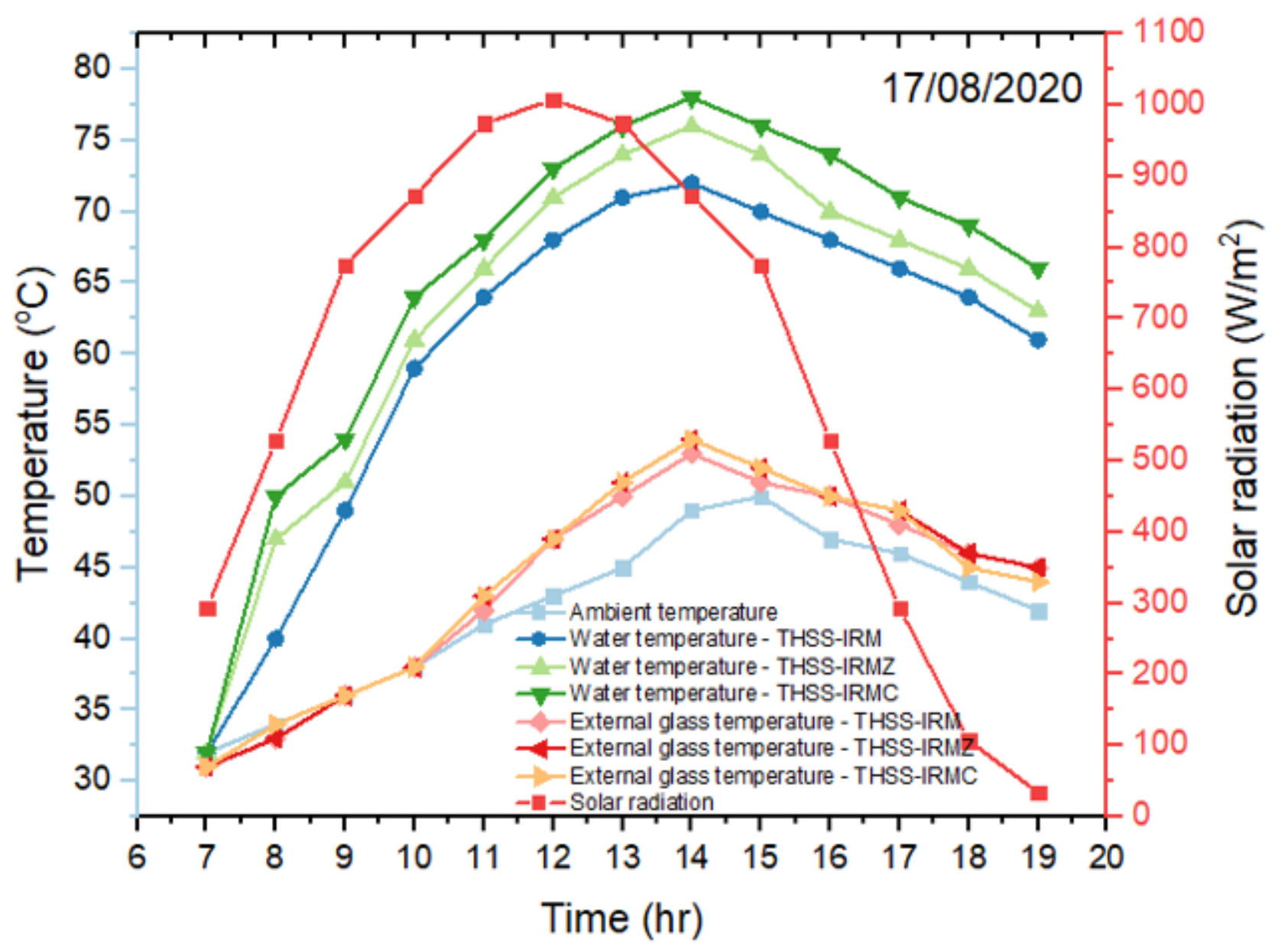

Figure 6

Environmental conditions for the test of solar stills at internal reflective mirrors and different basin metals (zinc and copper). 


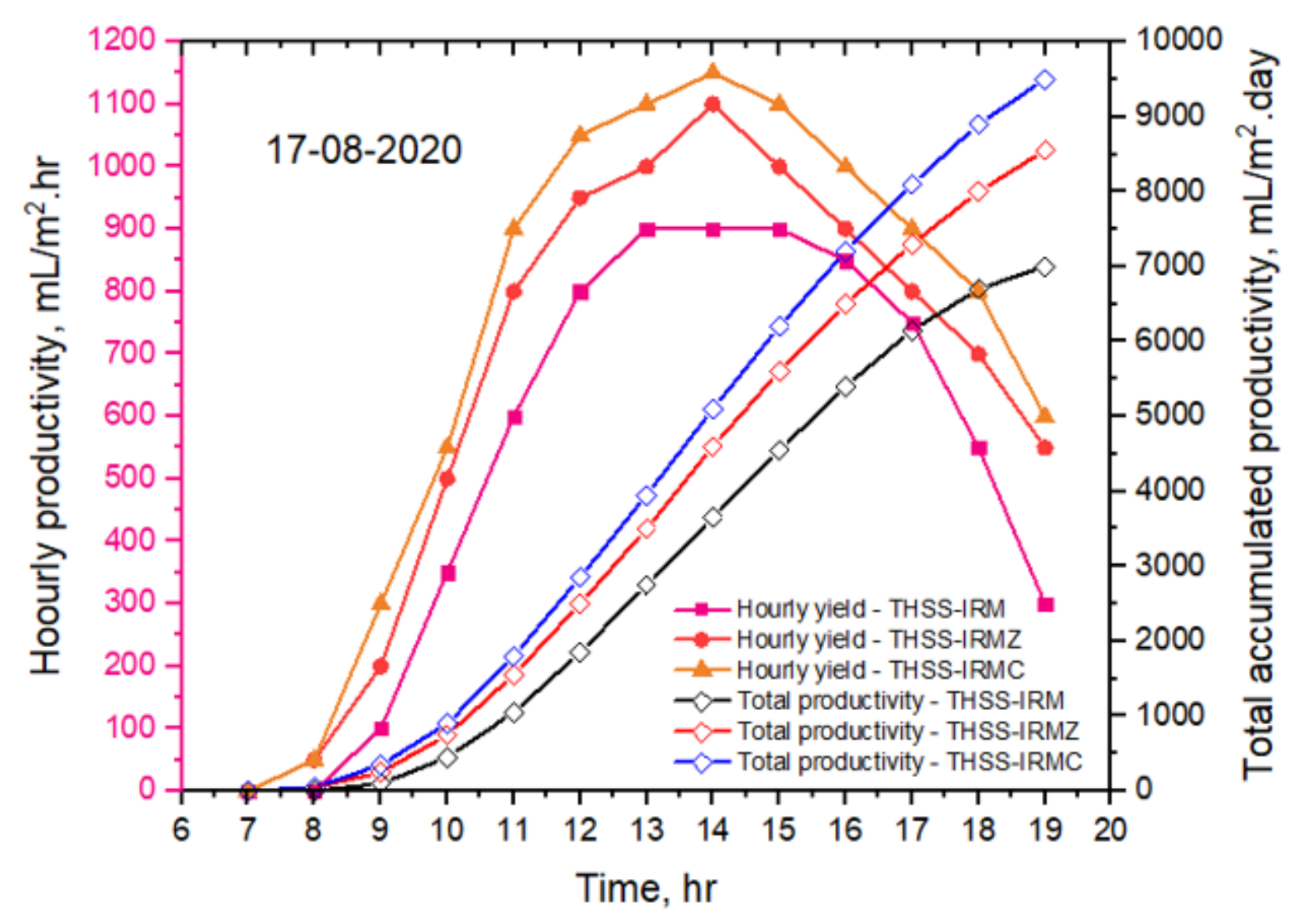

Figure 7

Instantaneous and total accumulated yield of the distillers (THSS-IRM, THSS-IRMZ, and THSS-IRMC). 


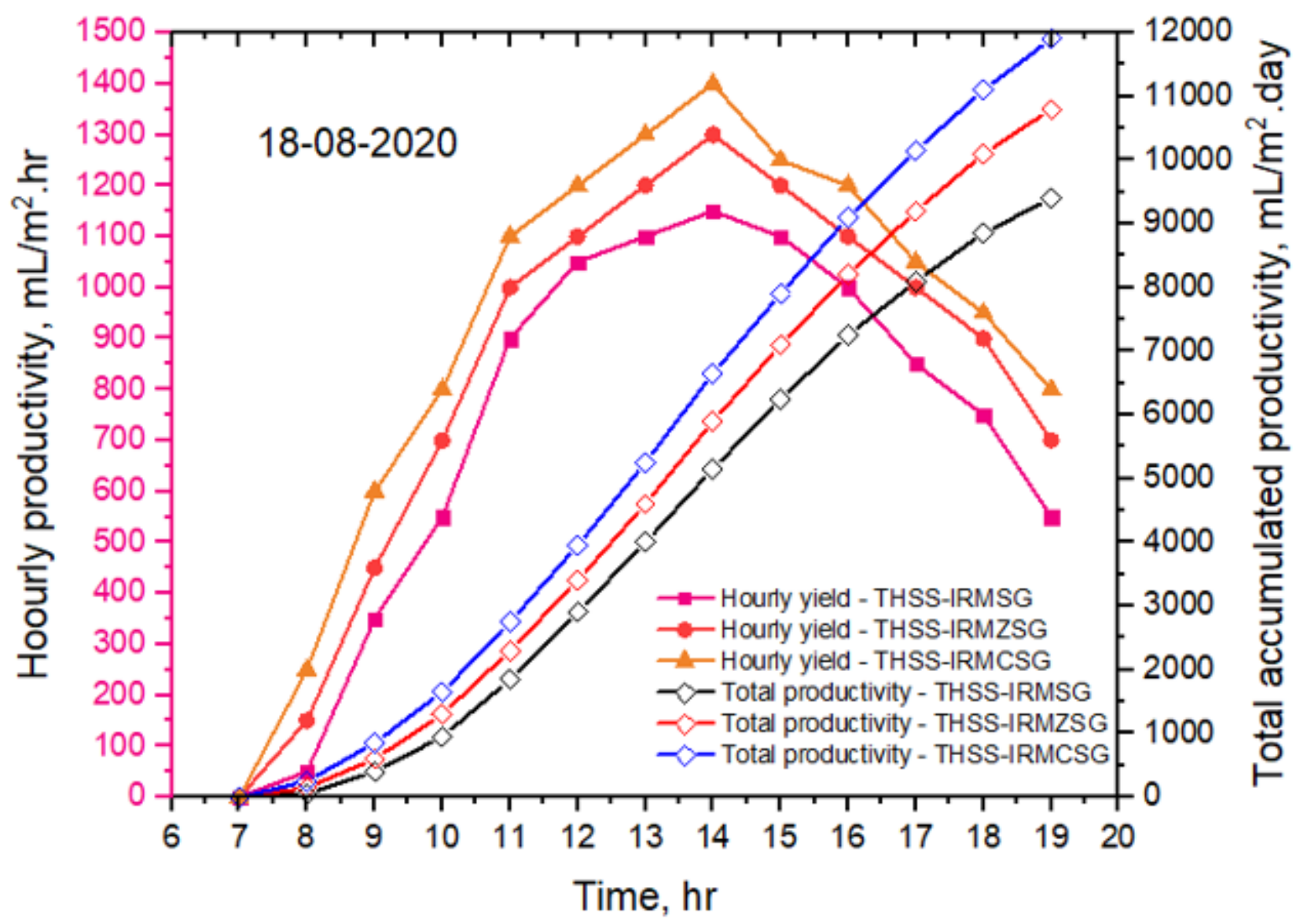

Figure 8

Instantaneous and total accumulated yield of the distillers (THSS-IRMSG, THSS-IRMZSG, and THSSIRMCSG). 